Index Copernicus Value: 83.27

ISSN (e)-2347-176x ISSN (p) 2455-0450

crossref DOI: _https://dx.doi.org/10.18535/jmscr/v5i6.78

Journal Of Medical Science And Clinical Research

\title{
Stapled Haemorrhoidopexy vs Conventional (Open) Haemorrhoidectomy--A Comparative Study
}

\author{
Authors \\ Dr Manawor Ahsan", Dr S. Nazir Hussain ${ }^{2}$ \\ ${ }^{1}$ Assistant Professor, Dept. of Surgery, NCMH, Patna \\ ${ }^{2}$ Associate Professor, Dept. of Surgery, NCMH, Patna
}

\begin{abstract}
Haemorrhoids are one of the most common anorectal disorders. Conventional haemorrhoidectomy $(\mathrm{CH})$ is the most commonly practiced surgical technique. Stapled Haemorrhoidopexy (SH) [procedure for prolapsed haemorrhoids (PPH)] is newly developed method for the surgical management of Haemorrhoids.

Method: Thirty patients admitted for surgical treatment of prolapse haemorrhoids were randomly assigned to conventional haemorrhoidectomy $(n=15)$ or stapled haemorrhoidectomy $(n==15)$. All patients received standardised preoperative antibiotics and laxative regime, visual analog scale (VAS) scores were used as a primary outcome measure. Secondary outcome measures were operative time use of analgesic, postoperative complications, hospital stay duration, and time of first bowel motion and return of normal activity.

Results: Stapled haemorrhoidectomy is associated with a significant less postoperative pain, early return to normal activity, shorter operative time, shorter hospital stay and early return to normal activity.

Conclusion: Stapled haemorrhoidectomy is an effective treatment of third degree \& $4^{\text {th }}$ degree haemorrhoid with significant advantages over conventional haemorrhoidectomy (CS).
\end{abstract}

Keywords: Haemorrhoids, Stapled Haemorrhoidopexy, Conventional Haemorrhoidectomy.

\section{Introduction}

Haemorrhoids are one of the most common anorectal disorders. Haemorrhoids or piles are dilated veins of the anal canal and are more common in obesity, constipation and pregnancy. Classically they occur in the 3, 7 and 11 o'clock position with the patient in lithotomy position. Symptoms of haemorrhoids are perrectal bleeding and prolapse. Bleeding is bright red in colour and which is painless. Haemorrhoids can be classified into 4 groups according to degree of haemorrhoids. Treatment of haemorrhoids depends on degree of haemorrhoids. Injection sclera therapy and banding for first degree and second degree haemorrhoids. Haemorrhoidectomy is indicated in third and fourth degree haemorrhoids. The Milligan-Morgan open haemorrhoidectomy is the most widely practiced surgical technique used for the management of third and fourth degree haemorrhoids and is considered the current "gold standard" though some early and late postoperative complications like anal pain, acute retention of urine, anal stenosis and incontinence is evident. Circular stapled Haemorrhoidopexy (SH) was first described by Longo in 1998 as an alternative to conventional excisional haemorrhoidectomy $(\mathrm{CH})^{4}$. Some study of randomized controlled trials comparing stapled Haemorrhoi- 
dopexy with traditional excisional haemorrhoidectomy has shown it to be less painful and that it is associated with quicker recovery $^{5-8}$.

The reports also suggest a better patient acceptance and a higher compliance with day-case procedures potentially making it more economical.

In some other randomized controlled trial study has reported that patients undergoing circular stapled Haemorrhoidopexy were significantly more likely to have recurrent haemorrhoids in long term follow up as well as significantly higher proportion of patients with stapled haemorrhoidectomy complained of symptoms of prolapse than those receiving conventional haemorrhoidectomy $(\mathrm{CH})^{9-12}$. Our study based onrandomized clinical trial to compare the results of using stapled haemorrhoidectomy verses conventional haemorrhoidectomy for treatment of 3rd \& 4th degreehaemorrhoid. ${ }^{1-3}$.

\section{Patient and Methods}

Our study is a single blinded randomized clinical trial comprising the use of stapled haemorrhoidectomy with conventional haemorrhoidectomy was conducted at Nalanda Medical College \& Hospital Patna between July 2014 to October 2016.In this study 30 patients with $3 \mathrm{rd} \&$ $4^{\text {th }}$ degree haemorrhoid were included for surgery after physical fitness. Patients were randomly allocated into two groups. one group of 15 patients each were randomised to conventional haemorrhoidectomy and second group of 15 patients were randomized to stapled haemorrhoidectomy.

\section{Operative Technique}

All patients were operated under spinal anaesthesia. All patients were given preoperative Injection ceftriaxone (1GM) and infusion metronidazole $(500 \mathrm{mg})$. Patients were given laxative at night and enema in the morning. All patients were operated in the lithotomy position. In conventional haemorrhoidectomy piles mass was hold with an artery forceps and dissected with diathermy and vascular pedicle was ligated with $1 / 0$ chromic catgut and excised and satisfactory haemostasis secured. Stapled haemorrhoidectomy were done by longo technique. Anal margin was well lubricated with xylocaine $2 \%$ gelly. Well lubricated circular anal dilator (CAD 33) is inserted and fixed with four anchoring stitches. The purse string sutureano scope (PSA33) is introduced through CAD33. The mucosa protrudes through PSA33 window. Purse string suture carried out 2-3 cm above the apex of the haemorrhoid. By rotating the PSA33 purse string suture is completed around the entire anal circumference. The haemorrhoidal circular stapler PPH33 is opened to its maximum position and introduced beyond the purse string. Purse string is tied with closing knot. Moderate traction on purse string, the prolapsedmucosa is accommodated by the casing of the PPH03. The instrument is closed completely by rotating the knob of the stapler clockwise up to the red indicator. Stapler is then fired and kept for 30 second for haemostasis.PPH03 is opened 3/4 and removed from anal canal. Analmucosa is inspected for haemostasis.

\section{Results}

The study conducted on 30 patients were divided into two groups. The majority of the patients have 3rd degree haemorrhoid (21 patients, $70 \%$ ). The main complain of the patients was anal bleeding (25 patients, 83\%).The clinical characteristics of patients in the two groups were similar regarding the mean age, gender, haemorrhoids degree and preoperative complaints $(\mathrm{P}>0.05)$.All patients were operated on lithotomy position under spinal anaesthesia. The operative time was significantly longer in the conventional group (mean=35 minutes) than the stapled group (ranged between 15 and 30 minutes with a mean of 25 minutes) Hospitalisation time ranged between 1 and 3 days. There was a significantly shorter mean duration of the hospital stay in stapled group than in the conventional group (1.09 verses 2.8 days, respectively). In 14 cases $(46.7 \%)$ the first bowel 
movement occurred while patients were still in hospital. There was a trend toward earlier bowel motions in the stapled group with $10(66.6 \%)$ patient opening their bowel within 24 hours after surgery in stapled group and $6(40 \%)$ in conventional haemorrhoidectomy with a significant difference. Earlier complications consisted of acute, urinary retention in 4 patients in conventional group whereas 2 in stapled group. Four patients $(26.6 \%)$ of stapled group complained of bleeding $\mathrm{P} / \mathrm{R}$ after operation that stopped within three days where as 7 patients $(46.6 \%)$ in open conventional group had bleeding $\mathrm{P} / \mathrm{R}$. Late complications such as anal stenosis, prolapsed recurrence, anal fissure and persistent pain not included in my study. Average pain in the stapled group was significantly lower than the open haemorrhoidectomy.

\section{Discussion}

In my study stapled Haemorrhoidopexy is associated with better postoperative pain control and early return to normal activity as compared to conventional haemorrhoidectomy. The use of VAS scores shows for conventional group, scores remain high at the end of 10days. Length of hospital stay was significantly different between two groups in this study. The patients of stapled group shown early discharge from hospital. Open haemorrhoidectomy is the most widely performed surgical operation for management of haemorrhoid and considered the Gold standard. Circular stapled Haemorrhoidopexy was first described by Longo in 1998 and early report shows better patients acceptance and higher compliance with day care procedure.

Senagore AJ et al done a prospective randomized controlled trial study ${ }^{3,17,18}$. A total of 156 patients (procedure for prolapse and haemorrhoids, 77; Ferguson, 79) completed randomization. One hundred seventeen patients (procedure for prolapse and haemorrhoids, 59; Ferguson, 58) returned for one-year follow-up. Demographic parameters, haemorrhoid symptoms, preoperative pain scores, and bowel habits were similar between groups. Postoperative pain during the first 14 days, pain at first bowel movement, and need for postoperative analgesics were significantly less in the procedure for prolapse and haemorrhoids group. Control of haemorrhoid symptoms was similar between groups.

Another prospective randomized multicentre control trial study done by Ganio E et $\mathrm{al}^{4,19,20}$ One hundred patients with symptomatic third and fourth-degree haemorrhoids were enrolled. After operation patients were completed 16 months follow up. They were evaluated in terms of postoperative pain control, recovery, hospital stay and maintaining normal continence to liquid stool. Patients in $\mathrm{CH}$ group complained of moderate pain for a median of 5.3 (range 0-19) days compared with 3.1 (range 0-10) days in SH group $(\mathrm{P}=0.01)$. The median hospital stay was 2 days in $\mathrm{CH}$ group compared with 1 day in group $\mathrm{SH}$ $(\mathrm{P}=0.01)$. In the early days after operation, patients in $\mathrm{SH}$ group had greater difficulty in maintaining normal continence to liquid stools $(\mathrm{P}=0.01)$, but after 30 days the continence score was better in $\mathrm{SH}$ group $(\mathrm{P}=0.04)$. Long term follow up regarding symptoms recurrence was not evaluated.

A review article published in 2007 , by Tjandra $\mathrm{JJ}$ et al of University of Melbourne ${ }^{29}$. A total of 25 randomized, controlled trials with 1,918 procedures were reviewed. The follow-up duration was from 1 to 62 months. Stapled Haemorrhoidopexy was associated with less operating time, earlier return of bowel function, and shorter hospital stay. There was less pain after stapled Haemorrhoidopexy, as evidenced by lower pain scores at rest and on defecation and 37.6 percent reduction in analgesic requirement. The stapled Haemorrhoidopexy allowed a faster functional recovery with shorter timeoff work, earlier return to normal activities and better wound healing. The patients' satisfaction was significantly higher with stapled Haemorrhoidopexy than conventional haemorrhoidectomy. Although there was increase in the recurrence of haemorrhoids at one year or more after stapled procedure (5.7 vs. 1 percent; 
odds ratio, 3.48; $\mathrm{P}=0.02$ ) and the overall incidence of recurrent haemorrhoidal symptoms.

Jayaramans et al reviewed randomized control trials from 1998 to May 2006 ${ }^{27}$. Patients undergoing circular stapled Haemorrhoidopexy (SH) were significantly more likely to have recurrent haemorrhoids in long term follow up at all time points than those receiving conventional haemorrhoidectomy $(\mathrm{CH})$ (7 trials, 537 patients). There were 23 recurrences out of 269 patients in the stapled group versus only 4 out of 268 patients inthe conventional group. Similarly, in trials where there was follow up of one year or more, $\mathrm{SH}$ was associated with a greater proportion of patients with haemorrhoid recurrence (5 trials, 417 patients). Furthermore, a significantly higher proportion of patients with $\mathrm{SH}$ complained of the symptom of prolapse at all time points (8 studies, 798 patients). In studies with follow up of greater than one year, the same significant outcome was found (6 studies, 628 patients,).

A recent review and meta-analysis done by chen JS et al from Taiwan ${ }^{30}$. They reviewed papers published between January 2000 and September 2009. These randomized, controlled clinical trials compared SH versus conventional haemorrhoidectomy. SH were superior to conventional haemorrhoidectomy with regard to operation time, early postoperative pain, urinary retention, and time to return to normal activity. However, skin tags and recurrent prolapse occurred at higher rates in the $\mathrm{SH}$ group.

A large number of recent reviews studied 81randomized control trials ${ }^{31-33}$. All these trials have shown a similar result in the long term follow up. There were no difference between stapled haemorrhoidectomy and open haemorrhoidectomy in terms of bleeding or postoperative complications. $\mathrm{SH}$ resulted in shorter operating times, hospital stay, and time to first bowel movement and return to normal activity. In the short term (between 6 weeks and a year) prolapse was more common after $\mathrm{SH}$. There was no difference in the number of patients complaining of pain between $\mathrm{SH}$ and $\mathrm{CH}$. In the long term (1 year and over), there was a significantly higher rate of prolapse after SH. There was no difference in the number of patients experiencing pain, or the incidence of bleeding, between $\mathrm{SH}$ and $\mathrm{CH}$. Significantly more interventions were undertaken after $\mathrm{SH}$ for prolapse at 12 months or longer.

\section{Conclusion}

Stapled haemorrhoidectomy is superior to conventional haemorrhoidectomy in terms of post-operative pain, operative time, duration of hospital stay and return to normal activity. Early functional and symptomatic outcome of stapled haemorrhoidectomy was satisfactory. But long term risk of prolapse and analstenosis and recurrence after stapled Haemorrhoidopexy is on is more with this operation. Cost of stapled haemorrhoidectomy is much higher than the open haemorrhoidectomy. If we consider the cost of surgery, recurrence of haemorrhoid, prolapse and analstenosis then conventional haemorrhoidectomy remains the "gold standard" in the surgical treatment of internal haemorrhoids.

\section{References}

1. Jayaraman S, Colquhoun PH, Malthaner RA. Stapled versus conventional surgery for haemorrhoids. Cochrane Database Syst Rev. 2006. 18; (4):CD005393.

2. Mattana C, Coco C, Manno A, Verbo A, Rizzo G, Petito L, et al. Stappled haemorrhoidopexy and Milligan Morgan haemorrhoidectomy in the cure of fourth degree haemorrhoids: long term evaluation and clinical results. Dis Colon Rectum 007; 50:1770-1775.

3. Senagore AJ, Singer M, Abcarian H. A prospective, randomized, controlled multicenter trial comparing stapled haemorrhoidopexy and Ferguson haemorrhoidectomy: perioperative and one-year results. Dis Colon Rectum. 2004; 47(11):1824-36.

4. Ganio E, Altomare DF, Gabrielli F, Milito G, Canuti S. Prospective randomized multicentre trial comparing stapled with 
open haemorrhoidectomy. $\mathrm{Br} \mathrm{J}$ Surg. 2001; 88(5):669-74.

5. Longo A. Treatment of haemorrhoids disease by reduction ofmucosa and haemorrhoidal prolapse with circular suturingdevice: new procedure. 6th World Congress of Endoscopic Surgery; Rome; 1998:777-784.

6. Corman ML, Gravié JF, Hager T, Arnaud JP, Pessaux P, Huten N,et al. Stapled haemorrhoidopexy: a consensus position paper byan international working partyindications, contraindications and technique. Colorectal Disease. 2001; 3:374-379.

7. Lan $\mathrm{P}, \mathrm{Wu} \mathrm{X}$, Zhou X,Wang J, Zhang L. The safety and efficacy ofstapled hemorrhoidectomy in the treatment of hemorrhoids: asystematic review and meta-analysis of ten randomized control trials. Int J Colorectal Dis 2006; 21:172-8.

8. Mehingan BJ, Monson JR, Hartley JE. Stapling procedure forhaemorrhoids versus Milligan-Morgan haemorrhoidectomy: randomized controlled trial. Lancet.2000; 355:782-785.

9. Rowsell M, Bello M, Hemingway DM. Circum ferentialmucosectomy (stapled haemorrhoidectomy) versus conventional haemorrhoidectomy: randomised controlled trial.Lancet. 2000; 355:779-781.

10. Ho YH, Cheong WK, Tsang C, Ho J, Eu KW, Tang CL, SeowChoenF. Stapled haemorrhoidectomy-cost and effectiveness.Randomized, controlled trial including incontinence score, anorectal manometry, and endoanal ultrasound assessments at upto three months. Dis Colon Rectum. 2000; 43:1666-1675.

11. Halaby R, Desoky A. Randomized clinical trial of stapled versusMilligan-Morgan haemorrhoidectomy. Br J Surg. 2001; 88:10491053.

12. Boccasanta P, Capretti PG, Venturi M, Cioffi U, De Simone M,Salamina G, et al. Randomised controlled trial between stapledcircumferential mucosectomy and conventional circular haemorrhoidectomy in advanced haemorrhoids with external mucosal prolapse. Am J Surg. 2001; 182:64-68.

13. Wilson MS, Pope V, Doran HE, Fearn SJ, BroughWA. Objective comparison of stapled anopexy and open haemorrhoidectomy: arandomised, controlled trial. Dis Colon Rectum. 2002; 45:14371444.

14. Pavlidis T, Papaziogas B, Souparis A, Patsas A, Koutelidakis I,Papaziogas T. Modern stapled Longo procedure vs. Conventional Milligan-Morgan haemorrhoidectomy: a randomized controlled trial. Int J Colorectal Dis. 2002; 17:50-53.

15. Gravie JF, Lehur PA, Huten N, Papillon M, Fantoli M, DescottesB, et al. Stapled Haemorrhoidopexy Versus MilliganMorgan Haemorrhoidectomy; Ann Surg. 2005; 242(1): 29-35.

16. Picchio M, Palimento D, Attanasio U, Renda R. Stapled vs open haemorrhoidectomy: long term outcome of a randomized controlled trial. Int $\mathrm{J}$ Colorectal Dis. 2006; 21: 668-669.

17. Smyth EF, Baker RP, Wilken BJ, Hartley JE, White TJ, Monson JR. Stapled versus excision haemorrhoidectomy: long-term follow-up of a randomized controlled trial. Lancet. 2003; 361:1437-1438.

18. Min-Hoe C, Ming-Hian K, Jit-Fong L, Kok-Sun K, Boon-Swee O. The evaluation of CEEA 34 for stapled haemorrhoidectomy: results of a prospective clinical trial and patient satisfaction. Am J Surg. 2009; 197:695-701.

19. Dixon MR, Stamos MJ, Grant SR, Kumar RR, Ko CY, Williams RA, et al. Stapled hemorrhoidectomy: a review of our early experience. Am j Surg. 2003; 69:862-5.

20. Habr-Gama A, Silva-e-Sousa AH, Rovelo JMC, Souza JS, Benício F, Regadas FS. Stapled haemorrhoidectomy: initial experience fa Latin American group. J Gastrointest Surg. 2003; 7: 809-813. 
21. Shao WJ, Li GC, Zhang ZH, Yang BL, Sun GD, Chen YQ. Systematic review and meta-analysis of randomized controlled trials comparing stapled haemorrhoidopexy with conventional haemorrhoidectomy. Br J Surg. 2008; 95(2):147-60.

22. Nahas SC, Borba MR, Brochado MC, Marques CF, Nahas CS, Miott-Neto B. Stapled haemorrhoidectomy for the treatment of haemorrhoids. Arq Gastroenterol. 2003; 40:35-39.

23. Sutherland LM, Burchard AK, Matsuda K, Sweeney JL, BokeyEL. A systematic review of stapled haemorrhoidectomy. Arch Surg. 2002; 137:1395-1406.

24. Nisar PJ, Acheson AG, Neal KR, Scholefield JH, Stapled hemorrhoidopexy compared with conventional haemorrhoidectomy: systematic review of randomized, controlled trials. Dis Colon Rectum. 2004; 47(11):1837-45.

25. Milligan ET, Morgan CN, Jones LE, Officer R. Surgical anatomy of the anal canal and operative treatment of haemorrhoids. Lancet 1937; 1119-1124.

26. Ferguson JA, Heaton JR. Closed haemorrhoidectomy. Dis Colon Rectum 1959; 2:1176-1179.

27. Jayaraman S, Colquhoun PH, Malthaner RA. Stapled haemorrhoidopexy is associated with a higher long-term recurrence rate of internal haemorrhoids compared with conventional excisional hemorrhoid surgery. Dis Colon Rectum 2007; 50(9):1297-305.

28. Hetzer FH, Demartines N, Handschin AE, Clavien PA. Stapled vs. excision haemorrhoidectomy long-term results of a prospective randomized trial. Arch Surg. 2002; 137:337-340.

29. Tjandra JJ, Chan MK. Systematic review on the procedure for prolapse and haemorrhoids (stapled haemorrhoidopexy). Dis Colon Rectum 2007; 50(6):878-92.
30. Chen JS, You JF. Current status of surgical treatment for haemorrhoids--systematic review and meta-analysis. Chang Gung Med J. 2010; 33(5):488-500.

31. Burch J, Epstein D, Baba-Akbari A, Weatherly H, Fox D, Golder S, et al. Stapled haemorrhoidectomy (haemorrhoidopexy) for the treatment of haemorrhoids: a systematic review and economic evaluation. Health Technol Assess. 2008; 12(8):iii-iv, ix-x, 1-193.

32. Madiba TE, Esterhuizen TM, Thomson SR. Procedure for prolapsed haemorrhoids versus excisional haemorrhoidectomy-a systematic review and meta-analysis, $\mathrm{S} \mathrm{Afr}$ Med J. 2009 99(1):43-53.

33. Burch J, Epstein D, Sari AB, Weatherly H, Jayne D, Fox D, Woolacott N. Stapled haemorrhoidopexy for the treatment of haemorrhoids: a systematic review. Colorectal Dis. 2009; 11(3):233-43. 